\title{
Discography in practice: a clinical and historical review
}

\author{
Joseph Walker III · Omar EI Abd · \\ Zacharia Isaac $\cdot$ Stefan Muzin
}

Published online: 13 November 2007

(C) Humana Press 2007

\begin{abstract}
Chronic low back pain is the most common cause of disability in individuals between the ages of 45 and 65 . Given the variety of anatomic and pathophysiologic causes of persistent low back pain, it is a difficult diagnosis for clinicians to treat. Discography is a diagnostic option that may link a patient's subjective complaints of spinal pain to symptomatic disk disease when non-invasive imaging, such as magnetic resonance imaging (MRI), does not find structural abnormalities. A controversial procedure, discography is only necessary to assess painful discs prior to surgical interventions. For accurate discogram interpretation an experienced spine interventionalist must be careful to exclude false positive results and be aware of the patient's underlying psychological state. This literature review will discuss the following: anatomy and function of the spine and intervertebral disc, intervertebral disc degeneration and discogenic pain, history of discography, indications and contraindications, a description of the procedure, complications, and the current debate regarding its outcomes.
\end{abstract}

Keywords Discography · Discogram - Spinal fusion . Internal disc disruption syndrome $\cdot$ Back pain

J. Walker III $(\bowtie) \cdot$ Z. Isaac $\cdot$ S. Muzin

Department of Physical Medicine and Rehabilitation,

Harvard Medical School, Spaulding Rehabilitation Hospital,

125 Nashua Street, Boston, MA 02114, USA

e-mail: jwalker8@partners.org

O. El Abd ( $\square)$

Department of Physical Medicine and Rehabilitation,

Newton Wellesley Hospital, 2000 Washington Street,

Newton, MA 02462, USA

e-mail: oleabd@Partners.org

\section{Introduction}

Approximately $50-80 \%$ of the US population will experience at least one episode of low back pain in their lifetime [1]. Almost 30\% of Americans suffer from low back pain at any given moment [2]. While the vast majorities of acute low back pain episodes are self-limited and ultimately resolve, approximately $20 \%$ of patients with low back pain will have a recurrence within 6 months [3]. Chronic low back pain is the most common cause of disability in individuals between the ages of 45 and 65 [2]. This disability has considerable medical, social, and economic implications. Annual direct and indirect medical costs of treating patients with low back pain are approximately 50 billion dollars. This places low back pain as the most costly musculoskeletal problem in the US [4].

Given the variety of anatomic and pathophysiologic causes of persistent low back pain, it is a difficult diagnosis for clinicians to make [5-7]. About $40 \%$ of these, difficult to diagnose, patients have a common pain generator: the intervertebral disc [8]. Identification of the pain generator guides clinicians in creating appropriate treatment and prognosis. Clinicians primarily use advanced imaging techniques, such as MRI to diagnose low back pain. However, many patients complain of low back pain, but have no structural abnormalities on MR imaging. Studies show that MRI findings, such as degenerative changes in disk morphology do not correlate with the presence or severity of low back symptoms or outcome [9-12]. These difficult cases require supplemental diagnostic studies. Discography is a diagnostic option that may link a patient's subjective complaints of spinal pain to symptomatic disk disease.

This literature review will discuss the following: anatomy and function of the spine and intervertebral disc, 
intervertebral disc degeneration and discogenic pain, history of discography, indications and contraindications, a description of the procedure, complications, and the current debate regarding its outcomes.

\section{Anatomy: structure of the vertebrae and function of the spine column}

The human spine has 7 cervical, 12 thoracic, 5 lumbar, and 5 fused sacral vertebrae. Cervical, thoracic, and lumbar vertebrae are composed of similar components. The anterior portion of the vertebra consists of the vertebral body. This structure provides support to the spine. The posterior portion of the vertebra consists of the spinous process and the lamina. Pedicles connect the posterior and anterior portions of the vertebral body. Intervertebral discs connect the inferior and superior vertebral bodies. The facet joints connect the inferior and superior posterior portion of the vertebra. Between the vertebral body and the intervertebral discs lie the vertebral end plates. Nutrition diffuses through these plates to support the intervertebral discs.

The functional purpose of the spinal column is to allow for flexibility and movement of the body and for protection of the spinal cord. As such, the spinal column carries the body's weight and distributes it through the pelvis. The most mobile portion of the spine is the occipitocervical junction, where the head articulates with the upper cervical spine. Movements in the cervical and lumbar regions include flexion, extension, rotation, and lateral bending. The thoracic region is less mobile due to its connections with the rib cage. The sacrum and coccyx are relatively immobile.

\section{Anatomy: structure of the intervertebral disc}

The intervertebral discs are complex structures that consist of a thick outer ring of fibrous cartilage, the annulus fibrosis, which surrounds a more gelatinous core known as the nucleus pulposus. The nucleus pulposus sits between the cartilage end plates. The intervertebral discs are approximately 7-10 $\mathrm{mm}$ thick and $4 \mathrm{~cm}$ in diameter in the lumbar region of the spine $[13,14]$.

The annulus is made up of a series of 15-25 concentric rings, or lamellae [15], with collagen fibers lying parallel to individual lamella. Elastin fibers lie between the lamellae, assisting the discs as they return to their original arrangement following flexion or extension. They may also bind the lamellae together as elastin fibers pass radially from one lamella to the next [16]. The cells of the annulus, particularly in the outer region, are often fibroblast-like, elongated, thin and aligned parallel to the collagen fibers.
Cells of the disc, both in the annulus and nucleus, can have several long, thin cytoplasmic projections, which may be more than $30 \mu \mathrm{m}$ long [17]. Such features are not often seen in cells of articular cartilage [18].

The central nucleus pulposus contains collagen and elastin fibers. They are organized randomly [19] and radially, respectively [20]. Collagen and elastin fibers are embedded in a highly hydrated proteoglycan-containing gel, aggrecan. This gel maintains tissue hydration through the osmotic pressure provided by its constituent chondroitin and keratin sulfate chains [21]. The proteoglycan and water content of the nucleus is greater than in the annulus. Additionally, several collagen types such as III, V, VI, IX, X, XI, XII, and XIV, small proteoglycans, such as lumican, biglycan, decorin and fibromodulin, and other glycoproteins, such as fibronectin and amyloid comprise the nucleus $[22,23]$. Research shows that collagen IX forms cross-links between collagen fibrils and maintains network integrity [24].

The third morphologically distinct region is the cartilage end plate, a thin horizontal layer of hyaline cartilage, which is less than $1 \mathrm{~mm}$ thick. The end plate articulates with the disc and the vertebral body. The collagen fibers within it run horizontal and parallel to the vertebral bodies. Some fibers extend into the disc itself [25].

\section{Anatomy: nerve supply of the intervertebral discs}

Two interconnected nerve plexuses, the anterior and posterior, innervate the individual cervical, thoracic, and lumbar discs. Both plexuses ultimately supply the annulus fibrosus with nerve innervation. Branches of two sympathetic trunks, the proximal ends of the gray rammi and the perivascular nerve plexuses of the segmental arteries [26, 27], form the anterior plexus. The anterior plexus supplies the anterior part of the disk. The posterior plexus supplies the posterior part of the disk.

The sinovertebral nerve is the primary contributor to the posterior plexus. Clinicians understand the sinovertebral nerve as the main nerve supply to every structure of the spinal canal. Luschka first described the sinovertebral nerve as entering the spinal canal through the intervertebral foramen and providing innervation to the posterior longitudinal ligament and the annulus fibrosis [28]. Later studies show that the sinovertebral nerve provides multiple ascending and descending branches [29] that eventually anastomose with one another [30,31]. Although the exact level of the anastomosis between the ascending and descending branches is uncertain, clinicians suspect it occurs at one or two levels above and below the level of entry into the canal [32]. Nakamura established that sympathetic trunks not only supply the anterior plexus, but also 
supply the nerves that innervate the posterior part of the lumbar vertebral discs [33].

\section{Anatomy: function of the intervertebral disc}

The intervertebral disc's primary functions are to transmit loads and facilitate movement between vertebral bodies [34]. When external forces transmit axial loads to the spine, the nucleus pulposus and the annulus fibrosus allow for pressure dispersal. Application of an axial load causes the gel-like nucleus pulposus to expand radially and exert a pressure on the band-like annulus [35]. Through a tension effect, annular resistance opposes this outward pressure. Like the radial belts on a tire, the annular fibers retain the shape of the disc during axial loading.

During movement, the annulus fibrosis behaves like a ligament and restrains movements to stabilize the vertebral joint [35]. The annular fibers provide resistance to vertical, horizontal, forward, backward, and lateral sliding movements. During twisting movements, the fibers in the direction of the twisting motion resist vertebral movement due to their oblique $60^{\circ}$ orientations. Repetitive twisting increases the susceptibility for microtears of annulus, which is one of the beginning pathways for degenerative disc changes.

\section{Disc degeneration: pathophysiology}

The first matrix changes occur in the center of the nucleus. These changes include fragmentation of matrix proteoglycans followed by a decrease in proteoglycan and water concentrations. This leads to an overall decline in the number of viable cells [36]. Proteoglycans in the matrix near the endplate regulate the movement of solutes in and out of the disc [37]. Removal of proteoglycans from the endplate accelerates the loss of proteoglycans from the nucleus as well as decreases disc hydration. Reduced lumbar artery blood flow also diminishes nutrition through the endplates into the matrix. Kauppila et al. reports an association among atherosclerosis, aortic calcification, reduced lumbar artery blood flow, increased incidence of disc degeneration, and subjective low back pain [38]. The morphologic degenerative changes in the disc lead to weakening of the annular structure, which makes it susceptible to tears. While imaging studies may show these tears as sources of pain, they may not be the primary pain generator.

The degeneration process of the intervertebral discs is associated with disc dehydration and desiccation of the nucleus. This process is typically asymptomatic. Disc degeneration alone does not cause back or neck pain.
However, in certain internal disc environments, a degenerative disc can be a source of pain.

\section{Disc degeneration: degenerative disc as the pain generator}

A tissue or structure might serve as a pain generator only if it is innervated. Pain derives from the disc itself, the disc's mechanical effect on neighboring structures, and inflammatory mediators affecting neighboring structures present because of a diseased disc.

An asymptomatic human lumbar disc contains nerve endings in the periphery of the outer annulus at a depth of a few millimeters [39]. Both the central endplate and periannular connective tissue are the most densely innervated structures in a normal disc. However, this innervation is limited to the very outermost structures [40]. This is not true in highly degenerative discs. Nerves here are not only in the periphery, but also may penetrate into the nucleus pulposus [41]. Most of these nerve fibers, which have been identified by immunochemistry, accompany blood vessels and control vaso-regulation. Coppes et al. postulates that the painful discs possess a greater amount of neurotransmitters than nonpainful discs [42]. Another set of neural structures independent of blood vessels express substance P. They have the same morphology as nociceptive nerve terminals. These findings emphasize the role of the neural structures in the degenerated disc and the pathophysiology of back pain.

As the annulus weakens and eventually tears, nuclear material touches passing nerve roots. This is another source of pain. A study by Olmarker in 1993 shows that nucleus pulposus tissue applied onto spinal nerve roots induces functional and morphological changes to the nerve roots [43]. These changes are often followed by intraradicular fibrosis and neural atrophy. Studies support the notion that disc cells express TNFa, which cause radicular abnormalities identical to those after nucleus pulposus application [44]. Additionally, studies show that selective inhibition of TNFa prevents thrombus formation, intraneural edema, and a reduction in porcine nerve root conduction velocity [45]. Other cytokines and inflammatory factors increase in patients with discogenic pain IL-6, IL-8 and acute phase reactant CRP [46-48]. Human and rat intervertebral discs have elevated levels of calcitonin gene related peptide (CGRP), vasoactive intestinal peptide (VIP), and substance $\mathrm{P}$ immunoreactive nerve fibers and phospholipase A2 [49, 50].

The herniated disc and resulting inflammatory factors stimulate nocioceptors in the posterolateral annulus, the ligamentum flavum, and the posterior longitudinal ligament, resulting in pain. A dorsal root ganglion touched by a herniated disc or inflammatory factors may also be involved in this painful process. 


\section{Disc degeneration: internal disc disruption syndrome}

Internal disc disruption syndrome (IDDS) offers an explanation for painful degenerative disk disease. In 1970, Crock conducted a large retrospective analysis of patients who continued to complain of disabling back and leg pain following operations for suspected disc prolapse. Crock reports the patients' histories, physical examinations, laboratory studies, and myelography as non-specific. Incapacitating back pain, depression, and weight loss characterized the patients' general clinical course. Although Crock finds no specific pathology, but postulates that "occult" discogenic pathology was the pain generator. He labels this pathology the IDDS. Alterations in the internal structure and metabolic function of one or more disk lead to IDDS. These alterations develop after significant trauma [51]. Subsequent studies establish the morphology of the disrupted disc as the degenerated nucleus pulposus with radial tears or fissures extending to the periphery of the annulus fibrosus [52]. A symptomatic degenerative disc is rendered painful in IDDS because of changes in its internal structure and radial fissures. Noncontrast imaging results show the disc's external appearance as normal. The fissures on CT discography are graded according to The Dallas Discogram Scale (see below). Patients with IDDS usually present with axial back pain that is dull or aching in quality, difficult to localize, and often produces somatically referred symptoms.

\section{Discography: indications for discography}

Discography is typically reserved for patients who report back pain for an extended period. Discography might prove effective for clinicians treating patients who have tried treatment modalities, such as modified activities, medications, physical therapy, injection procedures, and other conservative methods. Generally, discography is not clinicians' first diagnostic study of choice. It is currently performed only after other imaging studies are completed in order to obtain additional information for further management (Tables 1 and 2).

\section{Discography: injection mixture (injectate) [57]}

Three milliliter Omnipaque [Iohexol] $300 \mathrm{mg} \mathrm{I} / \mathrm{ml}$ is the contrast material. Some authors suggest combining

Table 1 Indications for discography [53-56]

Discography should be considered when

ALL of the following is present

If surgical management is a viable option ${ }^{\mathrm{a}}$

Pain is not responding to conservative treatment measures

Pain persists for an extended period of time (i.e., at least 3 months)

There is no evidence of contraindications such as severe spinal stenosis resulting in intraspinal obstruction, infection, or predominantly psychogenic pain

a Used to assess disc prior to spinal fusion. This will determine if the discs within the proposed fusion segment are symptomatic and if the discs adjacent to the surgical site are normal

b Used to distinguish between painful pseudoarthrosis or a symptomatic disc in a posteriorly fused segment

Table 2 Contraindications for discography

Specific contraindications for discography include, but are not limited to [57]

Systemic contraindications

(1) Patients with a known bleeding disorder and those on anticoagulation therapy

(2) Pregnancy

(3) Systemic infection or skin infection over the puncture site

(4) Allergy to contrast precludes testing with Omnipaque contrast; however, the test can be performed by Gadolinium contrast

(5) Psychiatric conditions such as PTSD or schizophrenia

Localized contraindications

(1) Solid bone fusion that does not allow access to the disc

(2) Severe spinal canal compromise at disc level to be investigated [58, 59]
At least ONE of the following is present
A high index of suspicion for discogenic pain where the pain is severe enough to consider surgical intervention
Failed back surgery ${ }^{\mathrm{b}}$


Table 3 Discography: medications [57]

\begin{tabular}{llc}
\hline Analgesics & Antibiotics & Contrast agent \\
\hline Lidocaine-MPF 1\% & $\begin{array}{c}\text { Cefazolin 1 g intravenously } \\
\text { within 1 h before procedure }\end{array}$ & $\begin{array}{c}\text { Omnipaque [Iohexol] injection, 300 mg I/ml nonionic } \\
\text { myelographic contrast medium }\end{array}$ \\
Bupivacaine hydrochloride-MPF 0.25\% & $\begin{array}{c}\text { Clindamycin } 600 \mathrm{mg} \text { intravenously } \\
\text { 1 h before procedure (if allergic to } \\
\text { cephalosporin or penicillin) }\end{array}$ & \\
& Gadolinium (if allergic to Omnipaque) \\
\hline
\end{tabular}

Table 4 Discography: instruments [57]

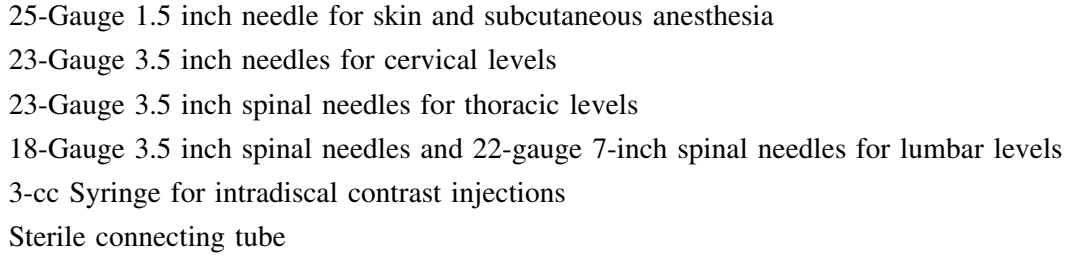

Omnipaque with $0.5 \mathrm{ml}$ of Cefazolin in an attempt to reduce the risk of discitis [60-62]; however, opponents report that injecting antibiotics into the nucleus can be accompanied by reduced cell metabolism and cell proliferation [63]. Given the low risk of discitis, inclusion of prophylactic antibiotic to the contrast material is not the standard of care [64] (Tables 3 and 4).

\section{Discography: patient preparation}

Clinicians must address any allergies to contrast, latex, or iodine as well as the need for prophylactic medications such as Benadryl and a steroid agent for allergy management. Options for patients with severe iodine contrast allergy include gadolinium contrast and saline. Patients might take fluids, but should not eat for $2 \mathrm{~h}$ before the procedure. Instructions regarding approved medications prior to the procedure vary.

Warfarin is stopped 5 days prior to the procedure. Plavix $^{\circledR}$ and Aggrenox ${ }^{\circledR}$ are stopped 1 week prior to the procedure to avoid bleeding. Pain medicines, anti-inflammatory medicines, sedatives, and any medicines that alter the patient's perception to pain should not be used the day of the procedure. This ensures that test results are not comprised. Blood pressure and pulse oxymetery should be monitored throughout the procedure.

\section{Discography: technique in lumbar region}

\section{Patient positioning}

Lumbar discography technique has evolved from a pure posterior approach utilized in the 1940s to the lateral and posterolateral approaches commonly used today [65]. The posterior approach, also known as the midline transdural approach, requires a dural puncture. Unless technically necessary, clinicians generally avoid this approach. A lateral approach involves placing the patient in a decubitus position [66].

The posterolateral approach involves placing the patient's body slightly oblique, rotated forward, and at a $45^{\circ}$ angle to the bed. Overall, the patient has less movement in this positioning. Placing the patient at a $45^{\circ}$ angle improves visualization of the lumbosacral junction and reduces the chance of contacting the iliac crest on needle insertion [67].

\section{Needle placement}

Most institutions, today, utilize high-resolution C-arm fluoroscopy when performing discography. Approaching the lumbosacral disc requires a cranial tilt of the $\mathrm{C}$-arm at roughly $45^{\circ}$. Tilting the $\mathrm{C}$-arm at $45^{\circ}$ allows for the clinician to have an optimal visualization of the disc space. The C-arm is then placed obliquely, so that under fluoroscopy the superior articulating process (SAP) is seen in the midportion of the disc space.

The lumbar discs superior to L5-S1 are generally easier to enter because the iliac crest lies lower and is typically not obstructing the view of the disc space. Usually, a straight anteroposterior view is sufficient for the L3-4 disc and the L2-3 disc, because both have a caudal tilt. For all injected discs clinicians should visualize the SAP at the edges of the endplates and at the midpoint of the disc [67].

After proper visualization, clinicians make a $0.5 \mathrm{cc}$ wheal of $1 \%$ lidocaine to anesthetize the skin. An 18-gauge 3.5-inch spinal needle is then inserted through the 
musculature at the same location as the wheal. Under fluoroscopy, clinicians place a needle via a right paramedian approach. The needle is positioned slightly lateral to the SAP and at a midpoint between the endplates. Once the needle is in the correct position, the stylet is removed. A 22-gauge 7-inch spinal needle is inserted via the 18-gauge 3.5-inch needle. The needle must pass lateral to the SAP yet medial to the exiting nerve root. Resistance and back pain will be noted on passing it through the annulus. Pain into the extremity likely suggests contact with the nerve root, at which point the needle is redirected. Once penetration into the disc occurs, antero-posterior and lateral images of the disc are obtained. The needle tip should be in the center of the disc space on both of these views [67]. Any deviation leads to the risk of annular injection of contrast. The procedure is repeated at all the levels to be tested. After all needles are introduced, the contrast is injected. A normal lumbar disc accepts from 1.5 to $3 \mathrm{ml}$ of fluid [68].

\section{Discography: technique in thoracic region}

\section{Patient positioning}

Thoracic discography is not routinely requested or performed. Simmons and Seigl may have provided the first documented description of dorsal disc injections in 1975 [69]. The patient is positioned prone.

\section{Needle placement}

Thoracic discography is performed in a similar fashion as lumbar discography with a few changes due to anatomical considerations. Pneumothorax and spinal cord injuries are considerable risks while performing thoracic discography. A single flexible 23-gauge 3.5-inch spinal needle is inserted instead of a 22-gauge 7-inch needle because it grants good needle control [70]. There is less soft tissue space in the thoracic area, thus a long needle is unnecessary. A steeper needle angle is taken to reach the center of the thoracic disc as compared to the lumbar disc because the facet joints are more coronally oriented [71].

A $0.5 \mathrm{cc}$ wheal of $1 \%$ lidocaine is made to anesthetize the skin. Under fluoroscopic guidance, the needle tip is aimed to a radiolucent rectangular space between the SAP and the costovertebral junctions to avoid contact with the thecal sac, pleura or the spinal cord.

Once in position contrast is injected. A normal thoracic disc accepts around $0.6 \mathrm{ml}$ of fluid, while a degenerative thoracic disc accepts around $2.5 \mathrm{ml}$ of fluid [72].

\section{Discography: procedure in cervical region}

Patient positioning

Smith and Nichols first described cervical discography in 1957 [73]. The patient is positioned supine with a cushion under the lower neck. For improved access to the upper and midcervical region the neck is hyper extended and slightly turned to right.

\section{Needle placement}

The cervical disc cannot be approached posteriorly because of the spinal cord, anteriorly because of the airway, or posterolaterally because of the vertebral artery. As such the cervical disc is approached anterolaterally. First, the soft tissues of the right neck and vascular structures are manually displaced laterally, while the esophagus and trachea is deviated medially. The carotid pulse is palpated. Under fluoroscopy, a 23-gauge 3.5-inch spinal needle is inserted between these structures via a right anterior oblique approach entering the right anterior portion of the disc and passing to the central part of the nucleus. Care is taken to not puncture the carotid. The midcervical discs are the easiest to access. The upper cervical discs are slightly more difficult due to trajectory requirements. The lower levels are also challenging due to difficulty seeing the cervical spine in a lateral view because of large or high riding shoulders.

Once in position the contrast is injected. A normal cervical disc accepts from 0.2 to $0.5 \mathrm{ml}$ of fluid, while a degenerative cervical disc accepts $0.5-1.5 \mathrm{ml}$ of fluid [74].

\section{Discography: interpretation}

Discography is only necessary to assess painful discs prior to surgical interventions. The pain must be predominantly axial and persisting for a substantial duration without improvement after conservative measures. The clinician performing the test must avoid false positive findings. We recommend the procedure without the use of conscious sedation or painkillers to avoid masking patients' pain sensation. This allows for a more accurate interpretation and localization of pain. Prior to conducting a discogram, clinicians must assess discs cephalic and caudal to the level of pathology in addition to a normal (control) disc. Clinicians assess the discs after inserting the needles into involved and control discs. Each disc is evaluated by four measures: the amount of pain provoked, the pressure measure within the disc, the volume of contrast injected, and the imaging findings. 
Table 5 Discographic pain provocation \& corresponding interpretations

\begin{tabular}{ll}
\hline VAS score & Significance \\
\hline P0 & No pain on injection this also includes a perceived sensation of pressure \\
P1 & Partial concordant pain (pain provoked partially covers the area of the usual pain) \\
P2 & Discordant pain (pain provoked in a different area than the usual pain) \\
P3 & Concordant back pain (pain provoked covers the same distribution of the usual pain) \\
\hline
\end{tabular}

Document pain location and intensity following each disc injection using the following visual analogue scale: Table 5.

The patient must remain blinded to the intervertebral disc tested. A discographic injection is considered "positive" if the pain response is P3 at the injected level. P1 response is a partial positive response and $\mathrm{P} 2$ is a negative response. Negative levels are control levels in each discographic study. Pain provocation is crucial before further interpretation of imaging findings. A positive level must be re-stimulated several minutes later to confirm findings. Non-painful discs with positive imaging findings are considered not significant. On the other hand, painful discs with negative imaging findings are considered inconclusive and repeating the test is recommended.

The volume of contrast injected varies between the cervical, thoracic and the lumbar regions. Normal discs in the lumbar region accommodate volumes reaching more than $3 \mathrm{ml}$. A positive correlation exists between the volume injected and the degree of annulus degeneration and annulus disruption.

Clinicians measure disc pressure through a manometer, which is connected to the inserted needle via a tube. The collected data includes opening pressure, pressure at onset of pain, and maximum pressure. Opening pressure is noted when dye is appreciated within the disc space. The disc is then pressurized until reaching $90 \mathrm{psi}(620.5 \mathrm{Kpa})$ or until pain is elicited. If pain is provoked at a pressure less than $15 \mathrm{psi}(103.5 \mathrm{Kpa})$, the disc is considered chemically sensitive. This indicates that the disc is highly sensitive and does not require increased pressure to respond. If pain is provoked between 15 and 50 psi $(103.5-344.7 \mathrm{Kpa})$, the disc is mechanically sensitive. If pain is provoked between 51 and 90 psi $(346.2-620.5 \mathrm{Kpa})$, investigating other sources of pain is recommended. If no pain is provoked by $90 \mathrm{psi}(620.5 \mathrm{Kpa})$, the disc is considered negative [75]. Many interventionalists do not use manometers and acquire "the feel" of the amount of contrast needed to pressure a disc. The integrity of the disc can be determined by assessing the amount of pressure it can hold. Lee et al. reports in 2003 that during intradiscal injections of discs with an intact annulus, annulus fibrosus pressures remain low, but there is an increase in intradiscal pressure [76]. Intradiscal pressures in an incompetent disc will decrease quite rapidly because of leakage of contrast. Imaging is assessed while performing the procedure under fluoroscopic guidance. The following imaging findings are noted under fluoroscopy during the procedure: Table 6, Fig. 1.

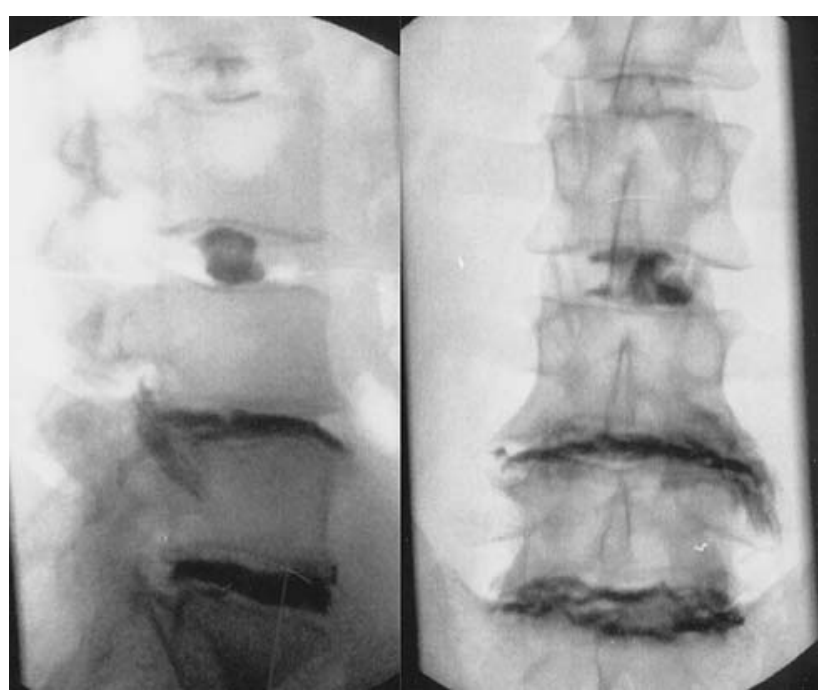

Fig. 1 Procedural fluoroscopic images of L2-S1 discogram: L2-3 disc and L3-4 are lobular, L4-5 and L5-S1 are irregular

Table 6 Discographic contrast imaging findings \& corresponding interpretations

\begin{tabular}{lll}
\hline & Imaging finding & Significance \\
\hline 1 & Cotton ball & No degeneration, soft amorphous nucleus \\
2 & Lobular & Mature disc with nucleus starting to coalesce into fibrous lumps \\
3 & Irregular & Degenerated disc with fissures and rents in the nucleus and inner annulus \\
4 & Fissured & Degenerated disc with radial fissures leading to the outer edge of the annulus. \\
5 & Ruptured & Disc has a complete radial fissure that allows injected fluid to escape. This can be any stage of degeneration \\
6 & End plate fracture & Disruption of end plate \\
\hline
\end{tabular}


Table 7 CT contrast imaging findings \& corresponding interpretations

The Dallas Discogram Scale

Annulus degeneration

(1) No change

(2) Local $<10 \%$

(3) Partial $<50 \%$

(4) Total $>50 \%$

Immediately following discography, computed tomography (CT) is performed. This is needed to confirm contrast injection into the nucleus pulposus. It also further assesses the annulus degeneration and the annular disruption. Contrast distribution with CT scan is assessed using The Dallas Discogram Scale [50] (Table 7, Figs. 2-6).

\section{Discography: complications}

Improved discography injection technique, imaging, and contrast materials have led to decreased complication rates since 1970. Overall complications associated with lumbar discography affect a range between $0 \%$ and $2.7 \%$ of patients. Around $0.6 \%$ of patients undergoing a cervical discogram are at risk for some complication [77]. Reported lumbar complications include transient exacerbations of pain, infectious discitis, and epidural abscess [78, 79]. Shreck et al. reports a nucleus pulposus pulmonary embolism in a single case study. They conclude that this complication occurred after spastic back

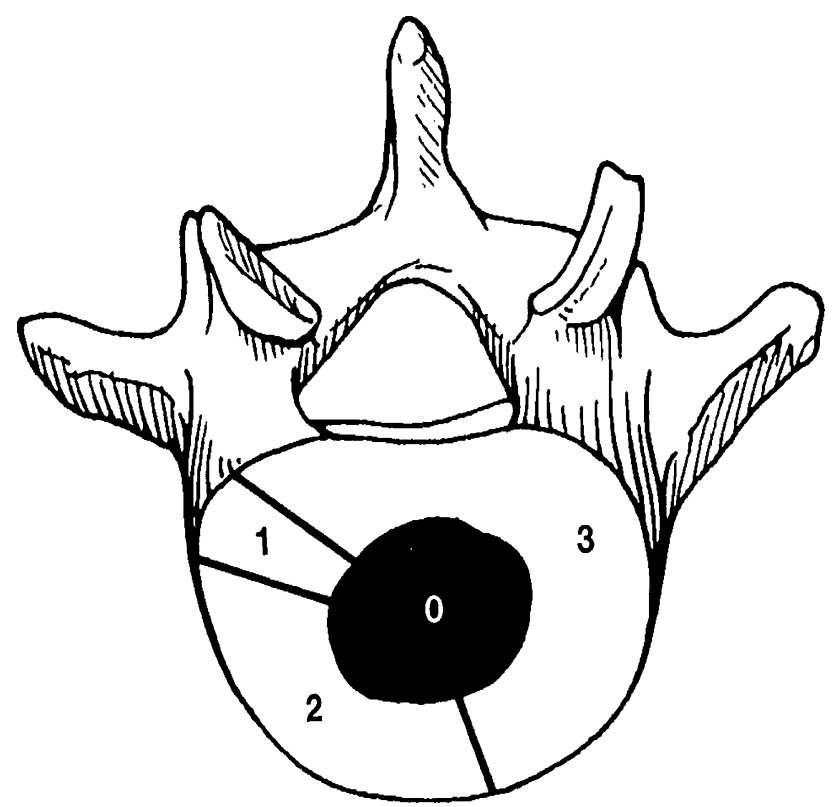

Fig. 2 Dallas annulus disc degeneration grades [50]

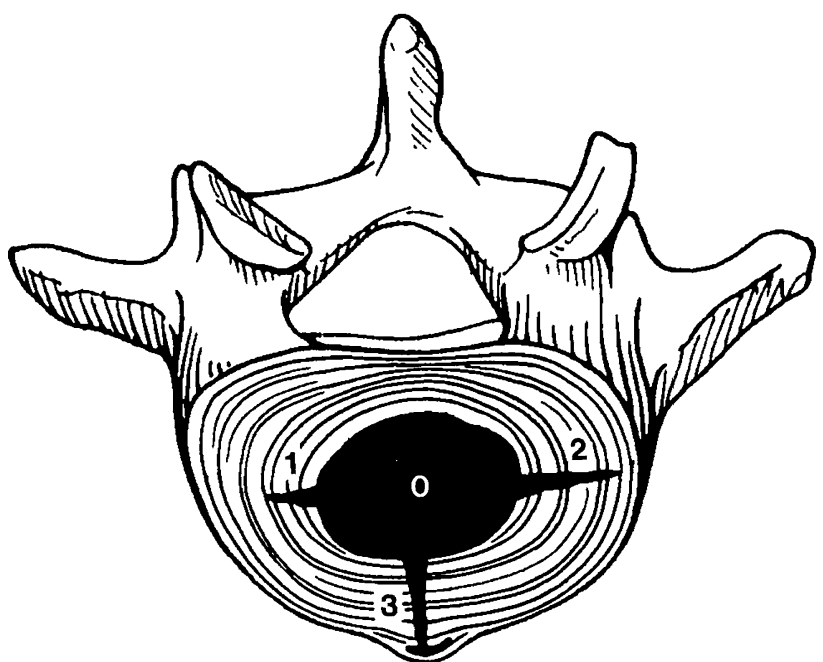

Fig. 3 Dallas annulus disruption grades [50]

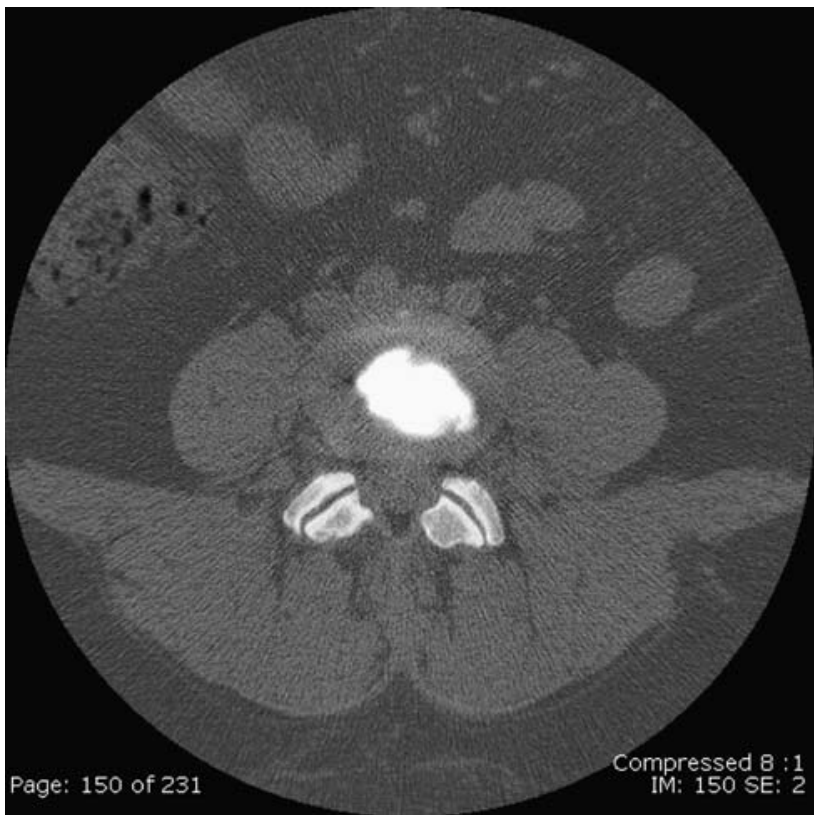

Fig. 4 Dallas grade 0 annulus disruption

extensions caused compressive forces on the vertebrae and propelled a fragment of the nucleus into the vertebral marrow sinusoids. This fragment then flowed into the anterior external vertebral plexus causing a pulmonary embolism [80]. Lumbar discography alone does not damage or cause normal discs to herniate [81]. A recent case series of five patients presented with acute lumbar herniation that occurred after provocative discography. Originally these discs had degenerative changes along with annular deficiencies [59].

Reported cervical discogram complications include discitis, epidural, subdural or retropharyngeal abscesses, or 


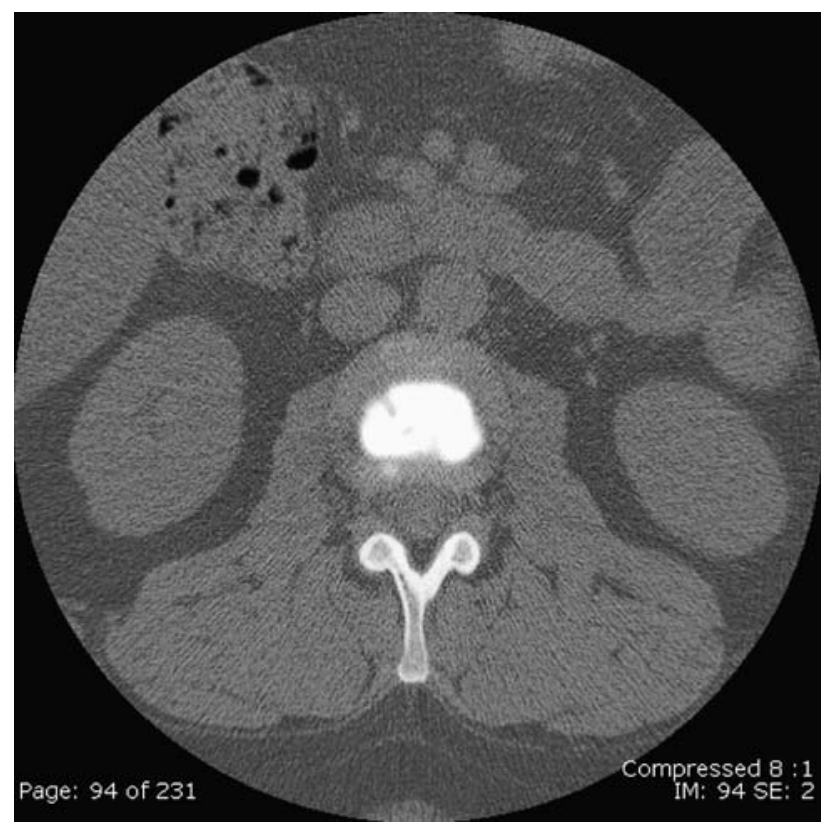

Fig. 5 Dallas grade 1 annulus disruption

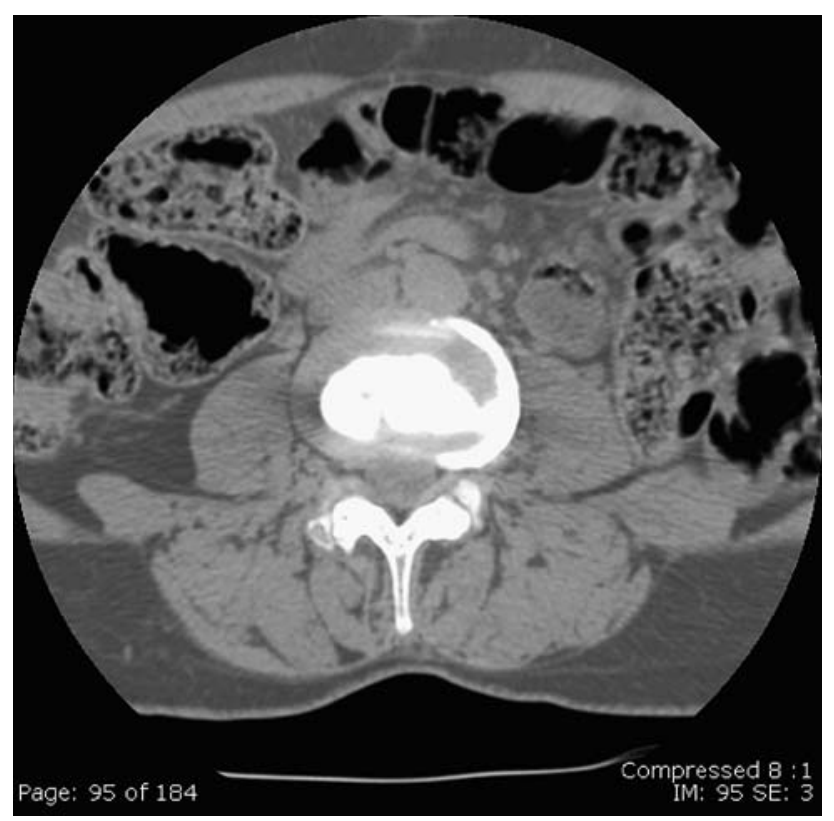

Fig. 6 Dallas grade 3 annulus disruption

neural injury [77, 82]. Spinal cord injury after cervical discogram is also quite rare; only a few case studies report complications. Laun et al. reports on a patient who developed teraplegia with radicular pain within seconds of an injection of contrast into the disc space [58]. Connor and Darden report on a patient who also developed C5 tetraplegia within days of the procedure [83]. Studies on complications specific to thoracic discograms are sparsely discussed in the literature.

The most common serious complication in cervical, thoracic, and lumbar discography is discitis. The incidence of post discography discitis in reported literature has varied from 5:2000 to $1: 30[84,85]$ and is generally rare [86-88]. The most common bacterial agent is Staphylococcus aureus and S. epidermidis [89]. Causes of cervical discitis are needle contamination, inadequate skin preparation, and inadvertent puncture of the esophagus [90]. Clinicians suspect post discography discitis if there is a marked increase of neck or back pain after the procedure along with an elevated sedimentation rate. Lumbar post-discography discitis resolves in $8-11$ weeks while cervical discitis resolves in 6-7 weeks [91]. Risk factors for postdiscogram discitis in the cervical region include male gender, presence of a beard, and thick neck [77]. One way to decrease the risk of discitis is to perform the procedure with a double needle technique [91]. Osti et al. recommend the use of broad-spectrum antibiotics as a preventive measure, but there is not enough evidence in the literature to justify the routine use of prophylactic antibiotics in lumbar discography $[61,92]$.

\section{History and controversy of discography}

During the 1940s and 1950s, many researchers conducted studies that answered questions regarding the pathophysiology of lumbar and cervical disc disease. Swedish radiologist Lindblom was the first to suggest a primary discogenic source of back pain in 1941. He performed the first discography when he injected red lead contrast into a cadaveric disc. His conclusion was, "diagnostic disc puncture with injection of opaque medium demonstrates disc ruptures and protrusions and tells if the patient's symptoms originate from the punctured disc" [93].

Soon after Lindblom, there was a large collection of literature regarding disc herniation. Hirsh published an article reporting no complications or disc damage in 16 patients who underwent discography [94]. His findings supported the safety of the procedure. Wise and Weiford performed the first discography in the US in 1950 [95]. Shortly, thereafter, Cloward first reported the clinical indications and technique of performing a discography in the US [96]. In the same year, Erlacher reported anatomic correlation with discography in 200 cadaveric discs [97]. The discography research expanded in the 1950s and 1960s and two camps developed among researchers. One camp expressed concern over the complications surrounding discography while the other camp touted it its safety and encouraged its use with difficult to treat patients. 
In 1968 Holt published a landmark article that questioned the credibility of discography [98]. Performing discographies on 30 volunteers from a penitentiary inmate population, Holt reports a $37 \%$ false-positive rate. He concludes the discogram-induced pain was caused by irritation of pain sensitive structures by the radiographic contrast dye rather than by the disc itself. While Holt addressed a central issue in the discography debate, other studies in 1968 evaluated discography and showed the positives of the procedure. Holt's paper resulted in a long lasting condemnation of discography that many clinicians still accept as true today. One large study by Wiley et al., which is often overlooked, ultimately supported discography as a diagnostic technique [99]. Simmons et al. [100] 1988 examination of Holt's paper showed described the paper as flawed and not applicable to the use of discography by present standards. Essentially, Simmons et al. discovered 4 flaws in Holt's paper. First, the contrast material, Hypaque, used by Holt may have irritated surround structures causing some of the false positive results. Secondly, improper needle placement noted in Holt's paper occurred because of a lack of CT or fluoroscopic imaging to confirm placement. Thirdly, Simmons et al. argues the questionability of the participant sampling as well as the motivation for participation. Lastly, there were notable errors in the accounting of the data.

Walsh et al. replicated Holt's study in 1990 by performing discography on seven patients with low-back pain and ten asymptomatic volunteers. The subjects were injected at three levels and all discographic sessions were videotaped. After each injection, the participant was interviewed about the pattern and intensity of the pain and the discs were imaged with CT. Walsh et al. defined the discogram as positive in cases when significant pain was associated with the injection and the disc showed radiographic signs of degeneration. Five of the ten asymptomatic participants radiographically showed at least one abnormal disc. None of the asymptomatic patients had significant pain with dye injection. Six out of the seven patients with low back pain had significant concordant back pain with dye injection. According to the discographic criteria used by Walsh et al. there was a false-positive rate of $0 \%$ and a specificity of $100 \%$.

The North American Spine Society (NASS) issued a position statements regarding lumbar discography in 1988 and 1995 [101].

In 1995 NASS recommended the use of discogram in patients who present with the following:

1. persistent back pain

2. negative imaging findings

3. suspected intervertebral disc abnormalities

4. being considered for spinal fusion surgery
Discography must be performed by those well experienced with the procedure and in sterile conditions with a double needle technique and fluoroscopic imaging for proper needle placement.

The recent controversy regarding the validity of discography is rooted based on several crucial points. The first point questions the diagnosis of IDDS and its role as an actual pain generator. Critics of the diagnosis of IDDS argue that the resultant pain with discography is not only due to a pure anatomical cause but is also confounded by current and past psychological overlay. The second point of contention is that discography is used to establish a diagnosis that has not been conclusively proven to exist nor has a universally accepted treatment. The last point argues that discography may lead to inappropriate surgery due to its high false positive rates and inconclusive post-surgical spinal fusion outcomes.

Supporters for the use of discography counter these points through a number of studies. Addressing the diagnosis of IDDS and its correlation to discography, Heggeness et al. finds a high incidence (72\%) of concordant pain with discography of the previously operated level. Further, he reports that persistence of a posterior annular defect was associated with a higher incidence of concordant pain [102]. Simmons et al. in 1991 also conducted a study with 164 patients who report low back pain and underwent discography and MRI. They found that discography and MRI results correlated in $80 \%$ of the cases. $76 \%$ of abnormal discs reproduced symptoms on discography [103].

Regarding surgical outcomes, Motimaya et al. performed a retrospective study evaluating 16 patients who underwent cervical spine fusion at levels in accordance with positive results on discogram [104]. They found that after discectomy and anterior fusion all 14 patients had good-to-excellent results at 6 months. Derby et al. conducted a retrospective study evaluating surgical outcomes after lumbar discography in 96 patients. He found that those who underwent interbody and combined fusion had significantly better outcomes than those who underwent intertransverse fusion. Nonsurgical patients had the poorest outcomes overall [75]. Lastly, Whitecloud et al. retrospectively reviewed 34 patients who had cervical fusion after positive discogram, $70 \%$ of the patients had good-toexcellent results [105].

Conversely, since 1998, Carragee, one of the leading authors on discography in recent years, addresses these same three points in a number of articles. Regarding the diagnosis of IDDS and psychological overlay, Carragee authored a number of articles and reports that patients who suffer from psychological disorders may be at an increased risk for inaccurate findings in discogram tests. Supplementing a study conducted by Walsh in 1996 regarding the 
effects of a patient's psychological state on accurate lumbar discogram findings, Carragee in 2000 [106] conducted a prospective study. He evaluated discography induced pain intensity and pain related behavior in patients with concurrent physiological disorders such as chronic pain and primary somatization disorders. In contrast to Walsh's study where the participants were young, healthy, and did not have a history of back pain, these participants were older and had a history of chronic pain. All 26 participants had degenerative disc changes on MRI. The authors report positive pain responses in $10 \%$ of those who were pain free, $40 \%$ of those with chronic cervical pain, and $83 \%$ of those with a somatization disorder. Additionally, $80 \%$ of patients receiving disability payments had a positive discography and $80 \%$ of patients with pending legal cases had positive discography. No patients reported pain with injection of radiographically normal levels. As such, Carragee discovered a strong correlation between positive findings on the psychological tests and a false positive discogram.

Carragee et al. [107] continued to follow the 26 patients from the above study to determine if discography causes new low back pain or the persistence of low back symptoms. From this prospective study, he found a correlation between patients who had back pain longer than 1-year post discography and significant emotional, psychological, and chronic pain problems. $66 \%$ of the somatization group and $40 \%$ of the participants with abnormal psychometric testing had significant back pain post injection. This included individuals without low-back pain but who had significant emotional and chronic pain problems. This study reveals that abnormal psychological testing may not only make interpretation of discographic results difficult but patients with such a psychological background may have back pain 1 year after the injection from the injection itself.

Also in 2000 [108] Carragee conducted a prospective observational study to investigate the clinical significance of a high intensity zone on lumbar MRI. A total of 42 patients with low back pain and 54 asymptomatic patients who had known risk factors for lumbar disc degeneration underwent physical examination, psychometric testing, plain radiograph, MRI, and discography. The presence of a high-intensity zone, annular disruption, and positive discographic pain were compared in the two groups. The symptomatic group showed the following results: $72.7 \%$ of discs with a high-intensity zone were positive on discography whereas $38.2 \%$ of the discs without a high-intensity zone were positive. The asymptomatic group showed the following results: $69.2 \%$ of the discs with a high intensity zone were positive on discography whereas $10 \%$ of the discs without a high-intensity zone were positive. Additionally, in patients with abnormal psychometric testing or chronic pain, $100 \%$ of the discs with a high intensity zone were positive on discography. The authors conclude that the presence of a high-intensity zone does not reliably indicate the presence of symptomatic disc disruption even though there is a higher incidence of a high intensity zone in discographically symptomatic patients. Primarily, the presence of abnormal psychometric testing or chronic pain may correlate with a positive discography.

Carragee et al. in 2000 [109] conducted a prospective observational study to determine the intensity of the pain response from discography in patients who underwent lumbar discectomy for intervertebral disc herniation. He compared 20 asymptomatic volunteers with normal psychometric scores, nearly perfect scores on standardized back pain rating instruments, and no other spinal pathology to a group of 27 symptomatic patients after single level discectomy with intractable low back pain syndrome. Seven patients in the latter group had normal psychometric testing. They found that a high percentage of asymptomatic patients with normal psychometric testing had significant pain on injection, a finding not significantly different from symptomatic patients with normal psychometric testing. However, patients with abnormal psychological profiles have significantly higher rates of positive disc injections.

Carragee [110] conducted a prospective study in 2004 to assess whether painful discography in asymptomatic patients is a predictor of subsequent low back pain (LBP) episodes. He recruited 50 subjects who reported no low back pain for clinical and psychometric testing, MRI scanning, and lumbar discography. A matched control group did not undergo discography. After determining which subjects had painful injections, all subjects were prospectively followed yearly for 4 years to determine the incidence of LBP and LBP disability. The authors report that there was a low incidence of LBP in both the experimental and control groups. They concluded that while painful disc injections were poor independent predictors of subsequent LBP episodes, psychological distress and preexisting chronic pain were strong predictors. Also, annular disruption was a weak predictor of future LBP.

Carragee has also questioned the validity of provocative discographic results irrespective of physiological overlay. He conducted a prospective study in 1999 to determine if patients could accurately discriminate between disc pain generated by a discographic injection and non-discogenic pain from proximal structures [111]. The study's eight participants did not have a history of low back pain, but did have degenerative disc changes on MRI and had undergone posterior iliac bone graft harvesting for unrelated non-low back reasons. The participants were asked to describe any pain experienced during discography as different, similar, or exactly like the pain experienced after bone graft harvest. Four out of the eight participants experienced severe 
pain with discographic injection exactly the same as that experienced with the bone grafting harvest procedure. Two of the four also showed signs of pain behavior with the discographic injection. As such, 4 out of $8(50 \%)$ patients met the criteria for both a positive discogram and lumbar fusion in clinical practice. This study questions the ability of a patient to separate concordant pain on discography from other non-spinal pain.

Carragee also conducted a retrospective data review in 2006 to determine if false-positive discographic results could be eliminated if pressure-limits were included in the criteria for positive discographic results [112]. Data from three prior studies were used resulting in 69 participants. Using the definition of a positive low-pressure injection as pain elicited from an injection with less than 22 psi higher than opening pressure, the authors found that a high number of asymptomatic patients without chronic low back pain (25\%) had false positive results in the form of positive low-pressure injections. The authors also found that positive injections were correlated with annular disruptions, abnormal psychometric findings, and chronic pain states.

Carragee et al. have also questioned basic discography proving internal disc disruption in two recent studies. In 2006 [113] they conducted a prospective study to evaluate the validity of a positive discography for the diagnosis of discogenic pain. They followed 32 patients over 5 years who initially presented with low back pain, had a positive single-level discogram, and underwent spinal fusion. Using patients who underwent spinal fusion for unstable lumbar spondylolisthesis as controls and adjusting for surgical morbidity and dropout, the best-case positive predictive value of discography was calculated to be $50-60 \%$. The authors concluded that positive discography was not highly predictive in identifying isolated intradiscal lesions causing chronic serious LBP.

Also in 2005 [114] Carragee et al. led a prospective longitudinal study of 100 subjects with numerous high risk factors for serious low back pain as determined by imaging and psychosocial characteristics. All subjects had risk factors for degenerative lumbar disc disease and a history of mild, persistent but non-disabling low back pain. All subjects were evaluated for lumbar spinal pathology by physical examination, plain radiography, and MRI. They also underwent psychological testing. A subgroup of psychologically normal patients also underwent provocative lumbar discography. They were followed for 6-month intervals for 5 years and assessed for disability due to low back pain. Carragee found that the development of disability due to serious low back pain was strongly associated with baseline psychosocial variables and less so with MRI changes and a positive discography. He also found that both vertebral endplate Modic changes seen on MRI and a positive discographic result were weakly associated with a future poor outcome. A limitation for majority of the earlier critical articles regarding discography and clinical outcomes, Carragee's included, is that spinal fusion is the ultimate treatment of choice. These studies may be measuring the efficacy of spinal fusion and not the predictability of discography. Given the new non-surgical interventional disc procedures such as IDET, discography may have a role in identifying patients appropriate for these procedures. Overall these studies illustrate the complicated history of the discogram and the controversy with which many clinicians continue to ponder.

\section{Conclusion}

We believe that only experienced interventionalists who can perform the test as well as interpret findings should perform discographies. Our conclusion is that discography is a low risk procedure for a properly selected patient. However, patients with significant co-morbid psychological conditions and/or with secondary gain issues should not be subjected to the test due to ample evidence of false positive findings in these patients as shown by Carragee. In order to interpret the validity of discographic test findings, the clinician must exclude false positive results. As recommended by NASS in its 1995 position statement, discography is recommended for patients with persistent pain in whom disc abnormalities are suspected and to assess the discs in patients in whom fusion is being considered. Discography helps surgical planning in this patient population. As noted in the above studies, discograms on suspected discs prior to surgery might improve surgical outcomes. However, further prospective randomized controlled studies are needed to evaluate outcomes of fusion after positive discography. Additionally more studies need to be done to evaluate the outcomes of various non-surgical disc interventions after positive discography, as well.

\section{References}

1. Andersson GB. Epidemiological features of chronic low-back pain. Lancet 1999;354(9178):581-5.

2. Frank JW, Kerr MS, Brooker AS, et al. Disability resulting from occupational low back pain: I. What do we know about primary prevention? A review of the scientific evidence on prevention before disability begins. Spine 1996;21:2908-17.

3. Cassidy JD, Cote P, Carroll LJ, Kristman V. Incidence and course of low back pain episodes in the general population. Spine 2005;30(24):2817-23.

4. Frymoyer JW, Cats-Baril WL. An overview of the incidences and costs of low back pain. Orthop Clin North Am 1991;22:263-71.

5. Burdorf A, Sorock G. Positive and negative evidence of risk factors for back disorders. Scand J Work Environ Health 1997;23:243-56. 
6. Garg A, Moore JS. Epidemiology of low-back pain in industry. Occup Med 1992;7:593-608.

7. Deyo RA, Phillips WR. Low back pain. A primary care challenge. Spine 1996;21(24):2826-32.

8. Schwarzer AC, Aprill CN, Derby R, Fortin J, Kine G, Bogduk $\mathrm{N}$. The prevalence and clinical features of internal disc disruption in patients with chronic low back pain. [see comment]. Spine 1995;20(17):1878-83.

9. Rothman RH. A study of computer-assisted tomography. Spine 1984;9:548.

10. Jensen MC, Brant-Zawadzki MN, Obuchowski N, Modic MT, Malkasian D, Ross JS. Magnetic resonance imaging of the lumbar spine in people without back pain. $\mathrm{N}$ Engl J Med 1994;331(2):69-73.

11. Modic M, Obuchowski N, Ross J, Brant-Zawadzki MN, Grooff PN, Mazanec DJ, Benzel EC. Acute low back pain and radiculopathy: MR imaging findings and their prognostic role and effect on outcome. Radiology 2005;237:597-604.

12. Borenstein DG, O'Mara JW Jr, Boden SD, Lauerman WC, Jacobson A, Platenberg C, Schellinger D, Wiesel SW. The value of magnetic resonance imaging of the lumbar spine to predict low-back pain in asymptomatic subjects: a seven-year follow-up study. J Bone Joint Surg Am 2001;83-A(9):1306-11.

13. Twomey LT, Taylor JR. Age changes in lumbar vertebrae and intervertebral discs. Clin Orthop 1987;224:97-104.

14. Roberts S, Menage J, Urban JPG. Biochemical and structural properties of the cartilage end-plate and its relation to the intervertebral disc. Spine 1989;14:166-74.

15. Marchand F, Ahmed AM. Investigation of the laminate structure of lumbar disc anulus fibrosus. Spine 1990;15:402-10.

16. $\mathrm{Yu}$ J, Peter $\mathrm{C}$, Roberts S, Urban JP. Elastic fibre organization in the intervertebral discs of the bovine tail. J Anat 2002;201:46575.

17. Bruehlmann SB, Rattner JB, Matyas JR, Duncan NA. Regional variations in the cellular matrix of the annulus fibrosus of the intervertebral disc. J Anat 2002;201:159-71.

18. Errington RJ, Puustjarvi K, White IR, Roberts S, Urban JP. Characterisation of cytoplasm-filled processes in cells of the intervertebral disc. J Anat 1998;192:369-78.

19. Inoue $\mathrm{H}$. Three-dimensional architecture of lumbar intervertebral discs. Spine 1981;6:139-46.

20. Yu J, Winlove CP, Roberts S, Urban JP. Elastic fibre organization in the intervertebral discs of the bovine tail. J Anat 2002;201:465-75.

21. Urban JP, Maroudas A, Bayliss MT, Dillon J. Swelling pressures of proteoglycans at the concentrations found in cartilaginous tissues. Biorheology 1979;16:447-64.

22. Roberts S, Menage J, Duance V, Wotton S, Ayad S. 1991 Volvo award in basic sciences: collagen types around the cells of the intervertebral disc and cartilage end plate: an immunolocalization study. Spine 1991;16:1030-8.

23. Melrose J, Ghosh P, Taylor TK. A comparative analysis of the differential spatial and temporal distributions of the large (aggrecan, versican) and small (decorin, biglycan, fibromodulin) proteoglycans of the intervertebral disc. J Anat 2001;198:3-15.

24. Eyre DR, Wu JJ, Fernandes RJ, Pietka TA, Weis MA. Recent developments in cartilage research: matrix biology of the collagen II/IX/XI heterofibril network. Biochem Soc Trans 2001;30:893-9.

25. Miller J, Schmatz C, Schultz A. Lumbar disc degeneration: correlation with age, sex, and spine level in 600 autopsy specimens. Spine 1988;13:173-8.

26. Bogduck N. The innervation of the lumbar spine. Spine 1983;8:286-93.

27. Weinstein J, Claverie W, Gibson S. The pain of discography. Spine 1988;13:1344-8.
28. Luschka, H. Die Nerven des menschlichen Wirbelkanales. Tiibingen: Laupp 1850.

29. Groen G, Baljet B, Drukker J. The innervation of the spinal dura mater; anatomy and clinical implications. Acta Neurochir 1988;92:39-46.

30. Pederson H, Blunck C, Gardner E. The anatomy of the lumbosacral posterior rami, meningeal branches of spinal nerves (sinuvertebral nerves). J Bone Joint Surg Am 1956;38-A:377-91.

31. Edgar M, Ghadially J. Innervation of the lumbar spine. Clin Orthop 1976;115:35-41.

32. Bogbuk N, Tynan W, Wilson A. The nerve supply to the human lumbar intervertebral discs. J Anat 1981;132:39-56.

33. Nakamura S, Takahashi K, Takahashi Y. Origin of the nerves supplying the posterior portion of the lumbar intervertebral discs in rats. Spine 1996;21:917-24.

34. Bogduk N, Twomey LT. Clinical anatomy of the lumbar spine. 2nd ed. London: Churchill Livingstone; 1991, p. 12.

35. Bogduk N, Twomey LT. Clinical anatomy of the lumbar spine. 2nd ed. London: Churchill Livingstone; 1991, p. 25.

36. Buckwalter JA. Aging and degeneration of the human intervertebral disc. Spine 1995;20:1307-14.

37. Roberts S, Urban JP, Evans H, Eisenstein SM. Transport properties of the human cartilage endplate in relation to its composition and calcification. Spine 1996;21(4):415-20.

38. Kauppila LI, McAlindon T, Evans S, Wilson PW, Kiel D, Felson DT. Disc degeneration/back pain and calcification of abdominal aorta. A 25 year follow-up study in Framigham. Spine 1997;22:1642-7.

39. Ashton IK, Roberts S, Jaffray DC, Polak JM, Eisenstein SM. Neuropeptides in the human intervertebral disc. J Orthop Res 1994;12:186-92.

40. Fagan A, Moore R, Vernon Roberts B, Blumbergs P, Fraser R. ISSLS prize winner: the innervation of the intervertebral disc: a quantitative analysis. Spine. 2003;28(23):2570-6.

41. Freemont AJ, Peacock TE, Goupille P, Hoyland JA, O'Brien J, Jayson MI. Nerve ingrowth into diseased intervertebral disc in chronic low back pain. Lancet 1997;350:178-81.

42. Coppes M, Marani E, Thomeer R. Innervation of "painful" lumbar discs. Spine 1997;22:2342-50.

43. Olmarker K, Rydevik B, Nordborg C. Autologous nucleus pulposus induces neurophysiologic and histiologic changes in porcine cauda equine nerve roots. Spine 1993;18:1425-32.

44. Igarashi T, Kikuchi S, Shubayev V, Myers RR. 2000Volvo Award winner in basic science studies: exogenous tumor necrosis factor-alpha mimics nucleus pulposus-induced neuropathology. Molecular, histologic, and behavioral comparisons in rats. Spine. 2000;25(23):2975-80.

45. Olmarker K, Rydevik B. Selective inhibition of tumor neucrosis factor-alpha prevents nucleus induced thrombus formation, intraneural edema and a reduction in nerve root conduction velocity: possible implications for future pharmacologic treatment strategies of sciatica. Spine 2001;26:863-9.

46. Le Gars L, Borderie D, Kaplan G, Berenbaum F. Systemic Inflammatory response with plasma $\mathrm{C}$-reactive protein elevation in disk-related lumbosciatic syndrome. Joint Bone Spine 2000;67:452-5.

47. Burke JG, Watson RWG, McCormick D, Dowling FE, Walsh MG, Fitzpatrick JM. Intervertebral discs which cause low back pain secrete high levels of proinflammatory mediators. J Bone Joint Surg (Br) 2002;84-B:196-201.

48. Oldenburg HS, Rogy MA, Lazarus DD, Van Zee KJ, Keeler BP, Chizzonite RA, Lowery SF, Moldawer LL. Cachexia and the acute-phase protein response in inflammation are regulated by interleukin-6. Eur J Immunol 1993;23:1889-94.

49. Moneta GB, Videman T, Kaivanto K, Aprill C, Spivey M, Vanharanta H, Sachs BL, Guyer RD, Hochschuler SH, 
Raschbaum RF, et al. Reported pain during lumbar discography as a function of anular ruptures and disc degeneration. A reanalysis of 833 discograms. Spine 1994;19(17):1968-74.

50. Sachs BL, Vanharanta H, Spivey MA, Guyer RD, Videman T, Rashbaum RF, Johnson RG, Hochschuler SH, Mooney V. Dallas discogram description. A new classification of CT/discography in low-back disorders. Spine 1987;12(3):287-94.

51. Crock H. A reappraisal of intervertebral disc lesions. Med J Aust 1970;1:983-89.

52. Bogduck N. The lumbar disc and low back pain. Neurosurg Clin N Am 1991;2:791-806.

53. Bini W, Yeung AT, Calatayud V, Chaaban A, Seferlis T. The role of provocative discography in minimally invasive selective endoscopic discectomy. Neurocirugia (Asturias, Spain) 2002;13(1):27-31; discussion 32.

54. Anderson MW. Lumbar discography: an update. [Review] [51 refs]. Semin Roentgenol 2004;39(1):52-67.

55. Kinard RE. Diagnostic spinal injection procedures. Neurosurg Clin N Am 1996;7(1):151-65.

56. Guarino AH. Discography: a review. Curr Pain Headache Rep 1999;3:473-80.

57. Fenton DS, Czervionke LF. Image-guided spine intervention, 1 st ed. Philadelphia: Saunders; 2003. ISBN 0-7216-0021-2, pp. 229.

58. Laun A, Lorenz R, Agnoli AL. Complications of cervical discography. J Neurosurg Sci 1981;25(1):17-20.

59. Poynton A, Hinman A, Lutz G, Farmer J. Discography-induced acute lumbar disc herniation: a report of five cases. J Spinal Disord Tech 2005;18(2):188-92.

60. Pobiel RS, Schellhas KP, Pollei SR, Johnson BA, Golden MJ, Eklund JA. Diskography: infectious complications from a series of 12,634 cases. Am J Neuroradiol 2006;27(9):1930-2.

61. Osti OL, Fraser RD, Vernon-Roberts B. Discitis after discography. The role of prophylactic antibiotics. J Bone Joint Surg Br 1990;72(2):271-4.

62. Klessig HT, Showsh SA, Sekorski A. The use of intradiscal antibiotics for discography: an in vitro study of gentamicin, cefazolin, and clindamycin. Spine 2003;28(15):1735-8.

63. Hoelscher GL, Gruber HE, Coldham G, et al. Effects of very high antibiotic concentrations on human intervertebral disc cell proliferation, viability, and metabolism in vitro. Spine 2000;25:1871-7.

64. Guyer RD, Ohmeiss DD. Lumbar discography: position statement from the North American Spine Society Diagnostic and Therapeutic Committee. Spine 1995;20:2048-59.

65. April, C. Diagnostic disc injection. Chapter 21, the adult spine, principles and practice. Raven Press; 1991.

66. McCulloch JA, Waddell G. Lateral lumbar discography. Br J Radiol 1978;51(607):498-502.

67. Tomecek FJ, Anthony S, Boxell C, Warren J. Discography interpretation and techniques in the lumbar spine. Neurosurg Focus 2002;13(2):E13.

68. Fenton DS, Czervionke LF. Image-guided spine intervention, 1st ed. Philadelphia: Saunders; 2003. ISBN 0-7216-0021-2, pp. 234.

69. Simmons EH, Segil CM. An evaluation of discography in the localization of symptomatic levels in discogenic disease of the spine. Clin Orthop Relat Res 1975;108:57-69.

70. Schellhas KP, Pollei SR, Dorwart RH. Thoracic discography. A safe and reliable technique. Spine 1994;19(18):2103-9.

71. Fenton DS, Czervionke LF. Image-guided spine intervention, $1 \mathrm{st}$ ed. Philadelphia: Saunders; 2003. ISBN 0-7216-0021-2, pp. 235.

72. Wood KB, Schellhas KP, Garvey TA, Aeppli D. Thoracic discography in healthy individuals. A controlled prospective study of magnetic resonance imaging and discography in asymptomatic and symptomatic individuals. Spine 1999;24(15):1548-55.

73. Smith GW, Nichols P. The technique of cervical discography. Radiology 1957;68:718-20.
74. Fenton DS, Czervionke LF. Image-guided spine intervention, 1st ed. Philadelphia: Saunders; 2003. ISBN 0-7216-0021-2, pp. 239.

75. Derby R, Howard MW, Grant JM, Lettice JJ, Van Peteghem PK, Ryan DP. The ability of pressure-controlled discography to predict surgical and nonsurgical outcomes. Spine 1999;24(4): 364-71.

76. Lee S, Derby R, Chen Y, Seo K, Kim M. In vitro measurement of pressure in intervertebral discs and annulus fibrosus with and without annular tears during discography. Spine J 2004;4(6): 614-8.

77. Zeidman S, Thompson K, Ducker T. Complication of cervical discography: analysis of 4400 diagnostic disc injections. Neurosurgery $1995 ; 37(3): 414-7$.

78. Junila J, Niinimaki T, Tervonen O. Epidural abscess after lumbar discography. A case report. Spine 1997;22(18):2191-3.

79. Guyer R, Ohmeiss D. Lumbar discography. Position statement from the North American Spine Society: Diagnostic and Therapeutic Committee. Spine 1995;20:2048-59.

80. Schreck RI, Manion WL, Kambin P, et al. Nucleus pulposus pulmonary embolism. A case report. Spine 1995;22:2463-6.

81. Kahanovitz N, Arnoczky SP, Sissons HA, Steiner GC, Schwarez P. The effect of discography on the canine intervertebral disc. Spine 1986;11(1):26-7.

82. Guyer RD, Ohnmeiss DD, Mason SL, Shelokov AP. Complications of cervical discography: findings in a large series. [Review] [14 refs]. J Spinal Disord 1997;10(2):95-101.

83. Connor PM, Darden BV 2nd. Cervical discography complications and clinical efficacy. Spine 1993;18(14):2035-8.

84. Wise RE, Weiford EC. X-ray visualization of the intervertebral disc, report of a case. Cleve Clin Q 1951;18:127.

85. Fraser RD. Chymopapain for the treatment of intervertebral disc herniation. The final report of a double-blind study. Spine 1984;9(8):815-8.

86. Wiltse LL, Widell ER Jr, Yuan HA. Chymopapain chemonucleolysis in lumbar disk disease. JAMA 1975;231(5):474-9.

87. McCulloch JA. Chemonucleolysis: experience with 2000 cases. Clin Orthop Relat Res 1980;146:128-35.

88. Brodsky AE, Binder WF. Lumbar discography: its value in diagnosis and treatment of lumbar disc lesions. Spine 1979;4:110-20.

89. Hoelscher GL, Gruber HE, Coldham G, Grigsby JH, Hanley EN Jr. Effects of very high antibiotic concentrations on human intervertebral disc cell proliferation, viability, and metabolism in vitro. Spine. 2000;25(15):1871-7.

90. Lownie SP, Ferguson GG. Spinal subdural empyema complicating cervical discography. Spine 1989;14(12):1415-7.

91. Guyer RD, Collier R, Stith WJ, Ohnmeiss DD, Hochschuler SH, Rashbaum RF, Regan JJ. Discitis after discography. Spine 1988;13(12):1352-4.

92. Willems PC, Jacobs W, Duinkerke ES, De Kleuver M. Lumbar discography: should we use prophylactic antibiotics? A study of 435 consecutive discograms and a systematic review of the literature. [Review] [31 refs]. J Spinal Disord Tech 2004;17(3):243-7.

93. Lindblom K. Diagnostic punture of intervertebral disc in sciatica. Acta Orthop Scand 1948;17:213-39.

94. Hirsh C. An attempt to diagnose the level of disc lesion clinically by disc puncture. Acta Orthop Scand 1948;18:132-40.

95. Wise RE, Weiford EC. X-ray visualization of the intervertebral disc. Cleve Clin J Med 1951;18:127-30.

96. Cloward RB, Buzaid LL. Discography; technique, indications and evaluation of the normal and abnormal intervertebral disc. Am J Roentgenol Radium Ther Nucl Med 1952;68(4):552-64.

97. Erlacher PR. Nucleography. J Bone Joint Surg Br 1952;34:20410.

98. Holt EP Jr. The question of lumbar discography. J Bone Joint Surg Am 1968;50(4):720-6. 
99. Wiley JJ, Macnab I, Wortzman G. Lumbar discography and its clinical applications. Can J Surg 1968;11(3):280-9.

100. Simmons JW, Aprill CN, Dwyer AP, Brodsky AE. A reassessment of Holt's data on: "The question of lumbar discography". [Review] [42 refs] Clin Orthop Relat Res 1988;237:120-4.

101. Guyer RD, Ohnmeiss DD. Lumbar discography. Position statement from the North American Spine Society Diagnostic and Therapeutic Committee. [see comment]. [Review] [89 refs]. Spine 1995;20(18):2048-59.

102. Heggeness MH, Watters WC, Gray PM. Discography of lumbar discs after surgical treatment for disc herniation. Spine 1997;22(14):1606-9.

103. Simmons JW, Emery SF, McMillin JN, et al. Awake discography. A comparison study with magnetic resonance imaging. Spine 1991;16(6 Suppl):S216-21.

104. Motimaya A, Arici M, George D, Ramsby G. Diagnostic value of cervical discography in the management of cervical discogenic pain. Conn Med 2000;64(7):395-8.

105. Whitecloud TS, Seago RA. Cervical discogenic syndrome. Results of operative intervention in patients with positive discography. Spine 1987;12(4):313-6.

106. Carragee EJ, Tanner CM, Khurana S, Hayward C, Welsh J, Date E, Truong T, Rossi M, Hagle C. The rates of false-positive lumbar discography in select patients without low back symptoms. Spine 2000;25(11):1373-80; discussion 1381.

107. Carragee EJ, Chen Y, Tanner C, Hayward C, Rossi M, Hagle C. Can discography cause long term back symptoms in previously asymptomatic subjects? Spine 2000;25(14):1803-8.
108. Carragee EJ, Paragioudakis SJ, Khurana S. 2000 Volvo award winner in clinical studies. Lumbar high-intensity zone and discography in subjects without low back problems. Spine 2000;25(23):2987-92.

109. Carragee EJ, Chen Y, Tanner CM, Truong T, Lau E, Brito JL. Provocative discography in patients after limited lumbar discectomy. A controlled, randomized study of pain response in symptomatic and asymptomatic subjects. Spine 2000;25(23): 3065-71.

110. Carragee EJ, Barcohana B, Alamin T, Haak EVD. Prospective controlled study of the development of lower back pain in previously asymptomatic subjects undergoing experimental discography. Spine 2004;29(10):1112-7.

111. Carragee EJ, Tanner CM, Yang B, Brito JL, Truong T. Falsepositive findings on lumbar discography. Reliability of subjective concordance assessment during provocative disc injection. Spine 1999;24(23):2542-7.

112. Carragee EJ, Alamin TF, Carragee JM. Low-pressure positive discography in subjects asymptomatic of significant low back pain illness. Spine 2006;31:505-9.

113. Carragee EJ, Lincoln T, Parmar VS, Alamin T. A gold standard evaluation of the "discogenic pain" diagnosis as determined by provocative discography. Spine 2006;31(18):2115-23.

114. Carragee EJ, Alamin TF, Miller JL, Carragee JM. Discographic, MRI, and psychosocial determinants of low back pain disability and remission: a prospective study in subjects with benign persistent back pain. Spine J 2005;5:24-35. 